\title{
Surveillance of Unruptured Intracranial Saccular Aneurysms Using Noncontrast 3D-Black-Blood MRI: Comparison of 3D-TOF and Contrast-Enhanced MRA with 3D-DSA
}

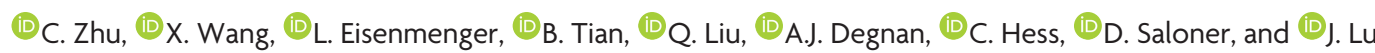 \\ 幽国国
}

\begin{abstract}
BACKGROUND AND PURPOSE: Patients with unruptured intracranial aneurysms routinely undergo surveillance imaging to monitor growth. Angiography is the criterion standard for aneurysm diagnosis, but it is invasive. This study aimed to evaluate the accuracy and reproducibility of a 3D noncontrast black-blood MR imaging technique for unruptured intracranial aneurysm measurement in comparison with 3D-TOF and contrast-enhanced MRA, using 3D rotational angiography as a reference standard.
\end{abstract}

MATERIALS AND METHODS: Sixty-four patients ( $57.3 \pm 10.9$ years of age, 41 women) with 68 saccular unruptured intracranial aneurysms were recruited. Patients underwent 3T MR imaging with 3D-TOF-MRA, 3D black-blood MR imaging, and contrast-enhanced MRA, and they underwent 3D rotational angiography within 2 weeks. The neck, width, and height of the unruptured intracranial aneurysms were measured by 2 radiologists independently on 3D rotational angiography and 3 MR imaging sequences. The accuracy and reproducibility were evaluated by Bland-Altman plots, the coefficient of variance, and the intraclass correlation coefficient.

RESULTS: 3D black-blood MR imaging demonstrates the best agreement with DSA, with the smallest limits of agreement and measurement error (coefficients of variance range, 5.87\%-7.04\%). 3D-TOF-MRA had the largest limits of agreement and measurement error (coefficients of variance range, $12.73 \%-15.78 \%$ ). The average coefficient of variance was $6.26 \%$ for 3D black-blood MR imaging, $7.03 \%$ for contrast-enhanced MRA, and $15.54 \%$ for TOF-MRA. No bias was found among 3 MR imaging sequences compared with 3D rotational angiography. All 3 MR imaging sequences had excellent interreader agreement (intraclass correlation coefficient, $>0.95$ ). 3D black-blood MR imaging performed the best for patients with intraluminal thrombus $(n=10)$.

CONCLUSIONS: 3D black-blood MR imaging achieves better accuracy for aneurysm size measurements compared with 3D-TOF, using 3D rotational angiography as a criterion standard. This noncontrast technique is promising for surveillance of unruptured intracranial aneurysms.

ABBREVIATIONS: $B B=$ black-blood; $C E=$ contrast-enhanced; $C V=$ coefficient of variance; $3 \mathrm{DRA}=3 \mathrm{D}$ rotational angiography; $\mathrm{IA}=$ intracranial aneurysm; $\mathrm{ICC}=$ intraclass correlation coefficient; $L O A=$ limit of agreement; $S P A C E=$ spatial and chemical-shift encoded excitation; UIA = unruptured intracranial aneurysm

ntracranial aneurysms (IAs) are common, with approximately $3 \%$ of adults having an unruptured IA (UIA). ${ }^{1}$ UIAs are associ- ated with morbidity and mortality due to the risk of rupture and the resultant subarachnoid hemorrhage. ${ }^{2}$ Of patients surviving ruptured IAs, 30\% will experience high morbidity due to associated intraparenchymal hemorrhage from late-onset complications such as vasospasm leading to cerebral infarction. Only approximately one-third of patients with subarachnoid hemorrhage related to IA rupture will fully return to their prior jobs, ${ }^{3,4}$ but diagnosis of IAs before rupture may improve patient outcomes. ${ }^{5}$

Clinical management of UIAs is based largely on aneurysm size and other features such as location, shape, and sac-to-neck

\footnotetext{
- Indicates open access to non-subscribers at www.ajnr.org

Indicates article with supplemental on-line table.

Indicates article with supplemental on-line photo.

http://dx.doi.org/10.3174/ajnr.A6080
} 
ratio, with saccular aneurysms being the most common type. ${ }^{6-9}$ Because intervention-associated risks may exceed the low rupture rates for smaller UIAs, ${ }^{5}$ most of those small aneurysms are followed with surveillance instead of immediate treatment. In addition, more incidental UIAs have been found on widely used noninvasive imaging techniques. Usually, incidental UIAs that are regular in shape and $<7 \mathrm{~mm}$ are followed up to assess changes with time that may modify clinical decision-making, ${ }^{10}$ but how to best diagnose and monitor UIAs remains uncertain.

Although 3D rotational angiography (3DRA) is the criterion standard for diagnosing IAs as well as evaluating IA morphology measurements, ${ }^{11}$ both MR imaging and CTA have become increasingly important in evaluating UIAs. This change is largely because both MR imaging and CTA are less invasive than 3DRA, reducing the risks of IA screening and monitoring of known UIAs. ${ }^{12-14}$ However, unlike MR imaging, both 3DRA and CTA expose patients to ionizing radiation and iodinated contrast media. MR imaging is an option that removes the uncertain risks of repeat radiation and contrast media exposure.

Vascular MR imaging has substantially improved with the development of techniques enabling the diagnosis, visualization, and assessment of intracranial aneurysms with high accuracy. ${ }^{15}$ Numerous studies have assessed the value of both flow-based (TOF) and contrast-enhanced (CE) MRA techniques. ${ }^{5}$ Fewer studies have evaluated 3D noncontrast black-blood (BB) MR imaging in aneurysm characterization, though early data have shown promise ${ }^{15}$ with the use of high-isotropic resolution (up to $0.5 \mathrm{~mm}$ ) to visualize the aneurysm geometry and wall. ${ }^{16} 3 \mathrm{D}-\mathrm{BB}$ MR imaging, however, has not been validated against 3DRA for aneurysm size measurements or compared with other clinical MRA techniques. This study aimed to compare black-blood MR imaging with 3D-TOF/CE-MRA for aneurysm size measurements using 3DRA as a reference standard. We hypothesized that $3 \mathrm{D}$ noncontrast $\mathrm{BB} \mathrm{MR}$ imaging can be used to measure aneurysm size accurately.

\section{MATERIALS AND METHODS \\ Study Population}

This study was approved by the institutional review board of Changhai Hospital. Informed consent was obtained from all patients. A total of 69 consecutive patients with confirmed saccular IAs were recruited between January 2016 and March 2018. All patients underwent 3T MR imaging and 3DRA within 2 weeks.

\section{Imaging Protocol}

MR Imaging. MR imaging was performed on a 3T whole-body MR imaging system (Magnetom Skyra; Siemens, Erlangen, Germany) using a 20-channel head coil. 3D-TOF-MRA, 3D-BB MR imaging, and CE-MRA were performed successively. The unenhanced 3D-TOF-MRA was performed with TR $=21 \mathrm{~ms}$, TE $=3.4$ $\mathrm{ms}$, flip angle $=20^{\circ}, \mathrm{FOV}=180 \times 200 \mathrm{~mm}^{2}$, matrix $=330 \times 384$, in-plane resolution $=0.5 \times 0.5 \mathrm{~mm}^{2}$, slice thickness $=0.7 \mathrm{~mm}$, 144 slices, and total acquisition time of 4 minutes 56 seconds. The 3D-BB MR imaging (spatial and chemical-shift encoded excitation [SPACE]) was performed with $\mathrm{TR}=900 \mathrm{~ms}$, $\mathrm{TE}=5.6 \mathrm{~ms}$, $\mathrm{FOV}=160 \times 160$, matrix $=320 \times 320$, slice thickness $=0.5 \mathrm{~mm}$, echo-train length $=60,280$ slices, and total acquisition time of 8 minutes 16 seconds. CE-MRA was then performed at the first pass of intravenous injection of Gd-DTPA at a dose of $0.1 \mathrm{mmol} / \mathrm{kg}$, using a FLASH $3 \mathrm{D}$ spoiled gradient-echo sequence with $\mathrm{TR}=$ $3.66 \mathrm{~ms}, \mathrm{TE}=1.44 \mathrm{~ms}, \mathrm{FOV}=182 \times 224 \mathrm{~mm}^{2}$, flip angle $=20^{\circ}$, matrix $=320 \times 320$, in plane resolution $=0.6 \times 0.7 \mathrm{~mm}^{2}$, slice thickness $=0.7 \mathrm{~mm}, 120$ slices, and total acquisition time of 1 minute 24 seconds.

3DRA. 3DRA was performed on the Artis zee Biplane angiographic system (VC14; Siemens). A 5-second DSA acquisition protocol was performed with contrast injection at a rate of $3 \mathrm{~mL} / \mathrm{s}$ of Ultravist (iopromide; Bayer HealthCare, Berlin, Germany). During the 5-second acquisition after a delay of 1 second, a $200^{\circ}$ rotation of the $\mathrm{C}$-arm was performed to obtain 133 frames. The parameters were as follows: $\mathrm{FOV}=320 \times 320 \mathrm{~mm}^{2}$, matrix $=$ $1024 \times 1024$.

\section{Image Analysis}

Image analysis was performed independently by 2 radiologists (X.W. and B.T. with 5 and 9 years of experience) who were blinded to patients' clinical data. All measurements were conducted on the postprocessing workstation (syngo X Workspace; Siemens). Measurement of 3DRA was performed on volume-rendered reconstruction, and measurements of TOF-MRA and CEMRA were performed on MIP reconstructions. The MIP images were imported to the workstation, and the image viewer automatically set a default window/level for the best display. In addition, 2 observers were also allowed to adjust the window/level and projection angles to best display the aneurysm and the parent vessel. Measurement of 3D-BB MR imaging was performed on MPR images.

For each IA, we measured the following parameters: 1) height: the maximum distance from the neck center to the dome of the aneurysm; 2) width: the longest diameter of an aneurysm perpendicular to the height; and 3) neck: the minimum width of the aneurysm at its junction with the parent vessel (Fig 1). Measurements were performed by the 2 readers (X.W. and B.T.) separately, with an interval of 2 weeks between different modalities. One reader performed the second measurement (X.W.) 2 weeks later using the same method to evaluate the intrareader variability. All these measurements were performed only for the luminal geometry, for which DSA could be used as a reference standard. If the aneurysms had intraluminal thrombus, the images were evaluated separately for the true aneurysm geometry.

\section{Statistical Analysis}

Normality assumptions were assessed using the Shapiro-Wilk test. Continuous variables were expressed as either mean $\pm \mathrm{SD}$ or median (interquartile range). Categoric variables were summarized by count (percentage). Comparisons of aneurysm height, width, and neck diameter among different imaging modalities were analyzed using the Kruskal-Wallis test. Measurement differences between MR imaging modalities and DSA as well as intraand interreader variabilities were assessed using the Bland-Altman analysis. Bias was assessed as the mean of the pair differences, and the $95 \%$ limits of agreement (LOA) were defined as bias \pm $1.96 \times$ SD. Measurement error was quantified by the coefficient of variance $(\mathrm{CV}=\mathrm{SD} /$ mean $\times 100 \%)$. Agreement between 
measurements was summarized by the intraclass correlation coefficient (ICC) with a 2 -way mixed model. An ICC value $>0.80$ indicated excellent agreement. On the basis of the measurement errors of each MR imaging sequence, the sample sizes needed to detect $5 \%, 10 \%$, and $20 \%$ changes in aneurysm size growth in longitudinal studies were calculated by using 0.9 power and .05 significance as described in a previous publication. ${ }^{17}$ Statistical analyses were performed using SPSS, Version 24.0 (IBM, Ar-

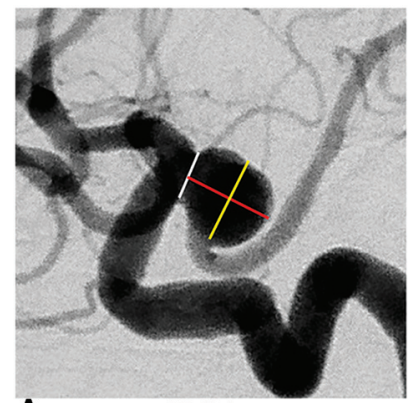

A DSA

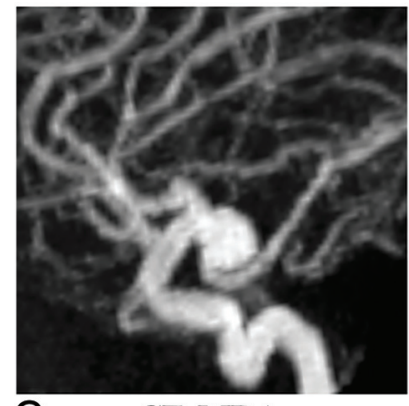

C CE-MRA
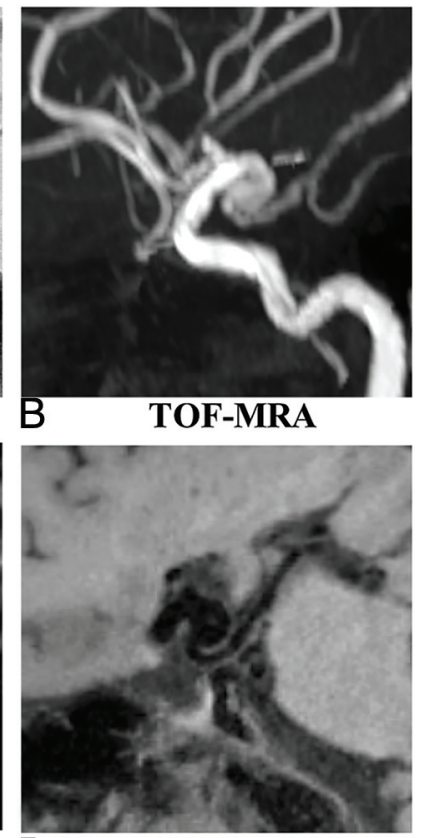

3D BB MR

FIG 1. A 61-year-old woman with a right posterior communicating artery aneurysm on DSA (A), TOF-MRA (B), CE-MRA (C), and 3D-BB MR imaging $(D)$. Aneurysm height (red line), width (yellow line), and neck (white line) measurements are demonstrated in $A$. monk, New York) and MedCalc for Windows, Version 9.4.2.0 (MedCalc Software, Mariakerke, Belgium).

\section{RESULTS}

Of the 69 recruited patients, 5 were excluded for the following reasons: 1$)$ an interval of $>2$ weeks between MR imaging and DSA $(n=2) ; 2)$ a ruptured aneurysm $(n=1)$; and 3$)$ insufficient image quality due to motion artifacts on $3 \mathrm{D}-\mathrm{BB} \mathrm{MR}$ imaging $(n=2)$. The remaining 64 patients $(57.3 \pm 10.9$ years of age, 41 women) with 68 saccular UIAs were included. UIAs were located in the internal carotid artery $(n=32)$, middle cerebral artery $(n=12)$, anterior communicating artery $(n=10)$, posterior communicating artery and posterior cerebral artery $(n=8)$, and vertebralbasilar artery $(n=6)$. The average interval between MR imaging and DSA was $2.2 \pm 1.6$ days (range, $1-9$ days). Mild flow artifacts were observed in 3 UIAs with aneurysm diameters of $>15 \mathrm{~mm}$ on 3D-BB MR imaging. These artifacts did not affect the measurement accuracy.

\section{Agreement between MR Imaging Sequences and DSA}

As shown in Table 1, there was no significant difference in aneurysm height, width, and neck diameter among TOF/CE-MRA, 3D-BB MR imaging, and DSA $(P>.05)$. Agreement of the quantitative measurements between MR imaging modalities and DSA is summarized in Table 2. Bland-Altman plots for each measurement are shown in Fig 2 and the On-line Figure. Measurements between MR imaging modalities and DSA showed excellent agreement with ICCs of $>0.96$. Measurement on TOF-MRA showed the largest variance (overall CV, 15.54\%) and higher LOA compared with measurements on CE-MRA (overall CV, 7.03\%) and 3D-BB MR imaging (overall CV, 6.26\%). Based on the measurement errors of each MR image, the calculated sample sizes in future longitudinal studies to detect $5 \%, 10 \%$, and $20 \%$ change in aneurysm growth are shown in Table 3. Compared with 3D-TOF, the use of CE-MRA or 3D-BB MR imaging reduces the sample size

Table 1: Comparison of aneurysm height, width, and neck measurements among MR and DSA imaging modalities ${ }^{\mathrm{a}}$

\begin{tabular}{lccccc}
\hline & TOF-MRA & CE-MRA & 3D-BB MRI & 3DRA & P Value \\
\hline Height $(\mathrm{mm})$ & $7.7(5.5-11.1)$ & $8.0(6.0-12.8)$ & $7.8(5.4-12.6)$ & $7.7(5.5-12.6)$ & .918 \\
Width $(\mathrm{mm})$ & $7.5(5.8-11.5)$ & $8.4(5.8-14.0)$ & $7.8(5.5-13.9)$ & $8.1(5.9-13.3)$ & .957 \\
Neck $(\mathrm{mm})$ & $6.8(5.3-10.4)$ & $6.7(5.2-10.6)$ & $7.0(4.8-10.2)$ & $6.9(4.6-9.8)$ & .774 \\
\hline
\end{tabular}

a Data are median (interquartile range)

Table 2: Comparison of MRI techniques with DSA for aneurysm measurements

\begin{tabular}{lcccccc}
\hline & Mean $(\mathbf{m m})$ & SD & CV (100\%) & Bias & LOA & ICC \\
\hline Height & & & & & & \\
TOF-MRA & 9.21 & 1.50 & 15.43 & -0.55 & $(-3.49-2.39)$ & $0.96(0.93-0.98)$ \\
CE-MRA & 9.90 & 0.62 & 6.32 & 0.14 & $(-1.08-1.36)$ & $0.98(0.97-0.99)$ \\
3D-BB MRI & 9.73 & 0.59 & 6.04 & -0.03 & $(-1.19-1.13)$ & $0.99(0.99-0.99)$ \\
Width & & & & & & \\
TOF-MRA & 9.53 & 1.56 & 15.78 & -0.33 & $(-2.73-3.39)$ & $0.96(0.94-0.97)$ \\
CE-MRA & 10.12 & 0.61 & 6.18 & 0.26 & $(-0.94-1.46)$ & $0.99(0.98-0.99)$ \\
3D-BB MRI & 9.96 & 0.58 & 5.87 & 0.10 & $(-1.04-1.24)$ & $0.99(0.99-0.99)$ \\
Neck & & & & & & \\
TOF-MRA & 8.00 & 0.98 & 12.73 & 0.31 & $(-1.61-2.23)$ & $0.96(0.93-0.98)$ \\
CE-MRA & 8.08 & 0.68 & 8.81 & 0.39 & $(-0.94-1.72)$ & $0.97(0.95-0.99)$ \\
3D-BB MRI & 7.71 & 0.54 & 7.04 & 0.02 & $(-1.04-1.08)$ & $0.98(0.98-0.99)$ \\
Overall & & & & & & \\
TOF-MRA & 8.91 & 1.41 & 15.54 & -0.19 & $(-2.95-2.57)$ & $0.96(0.95-0.97)$ \\
CE-MRA & 9.37 & 0.64 & 7.03 & 0.26 & $(-0.99-1.51)$ & $0.98(0.98-0.99)$ \\
3D-BB MRI & 9.14 & 0.57 & 6.26 & 0.03 & $(-1.08-1.15)$ & $0.99(0.99-0.99)$ \\
\hline
\end{tabular}



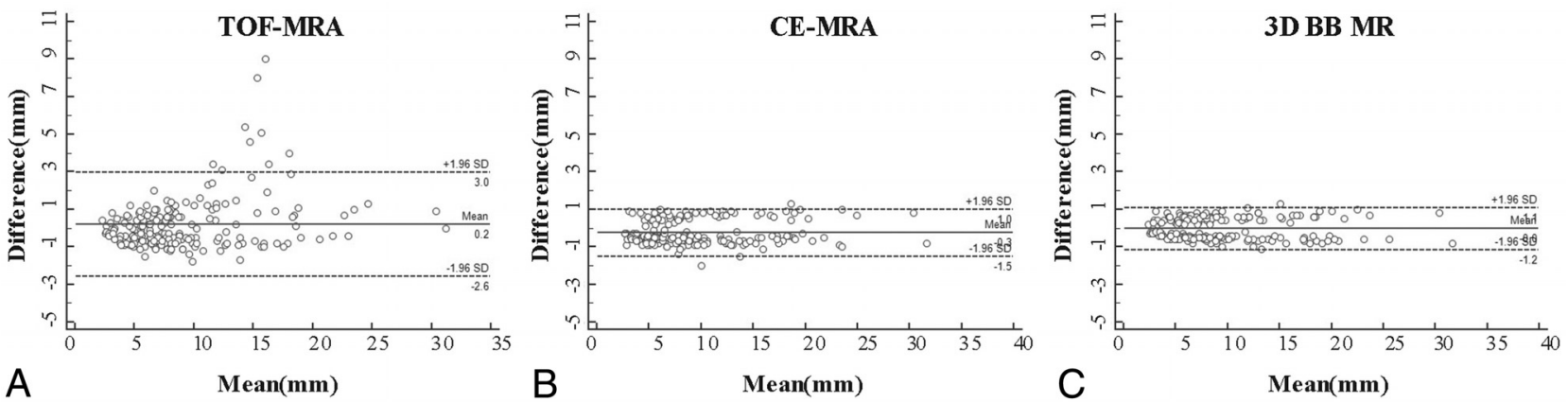

FIG 2. Bland-Altman plots of aneurysm measurements of TOF-MRA (A), CE-MRA (B), and 3D-BB MR imaging (C) versus 3DRA as the reference standard. Solid horizontal lines define the reference standard, and upper and lower dashed lines define the LOA.

Table 3: Sample size calculation using different MRI sequences to detect aneurysm growth

\begin{tabular}{lccc}
\hline $\begin{array}{c}\text { Aneurysm } \\
\text { Growth }\end{array}$ & $\begin{array}{c}\text { TOF-MRA } \\
\text { (CV = 15.54\%) }\end{array}$ & $\begin{array}{c}\text { CE-MRA } \\
\text { (CV = 7.03\%) }\end{array}$ & $\begin{array}{c}\text { SPACE } \\
\text { (CV = 6.26\%) }\end{array}$ \\
\hline $5 \%$ & 406 & 84 & 66 \\
$10 \%$ & 102 & 21 & 17 \\
$20 \%$ & 26 & 6 & 5 \\
\hline
\end{tabular}

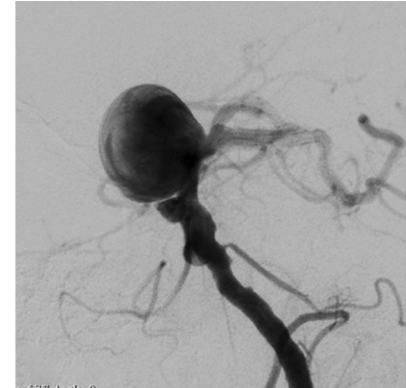

A

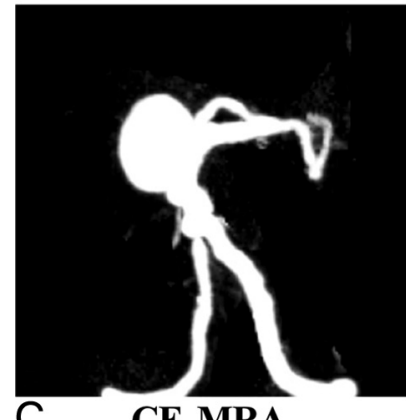

CE-MRA

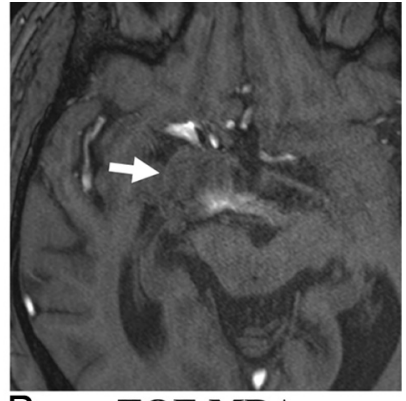

TOF-MRA

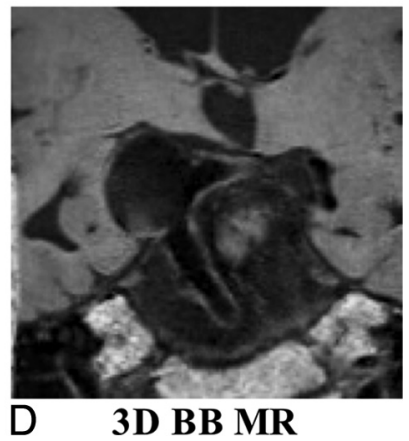

FIG 3. A 53-year-old man with multiple basilar artery aneurysms on DSA $(A)$. The aneurysm shows isointensity on TOF-MRA $(B)$ because of the slow flow (arrow). The aneurysm sac and neck were integrally visualized on CE-MRA $(C)$ and 3D-BB MR imaging $(D)$.

by $79 \%$ and $84 \%$, respectively. Comparisons of MR imaging modalities with DSA for aneurysm measurements by locations are summarized in On-line Table. The measurement errors did not vary significantly across locations.

Sample patient images are shown in Figs 3 and 4. Figure 3 shows that TOF is limited as a means of displaying the aneurysm geometry due to severe flow artifacts, while DSA, CE-MRA, and SPACE characterize the geometry nicely. Figure 4 shows an aneurysm with intraluminal thrombus. 3D-BB MR imaging can clearly show the entire aneurysm structure including both the lumen and the thrombus.

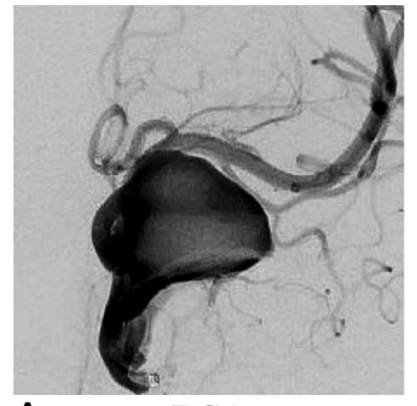

A DSA

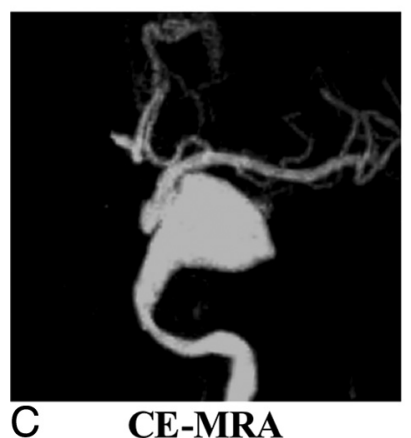

\section{B TOF-MRA}

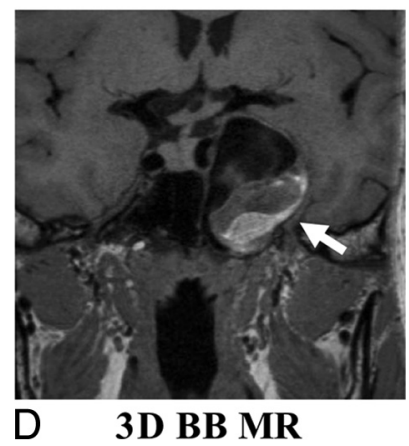

FIG 4. A 63-year-old woman with a right middle cerebral artery aneurysm on DSA (A). 3D-BB SPACE $(D)$ can clearly visualize the sac and intraluminal thrombus of the aneurysm, which is superior to DSA $(A)$, TOF-MRA $(B)$, and CE-MRA $(C)$.

\section{Intra- and Interreader Agreement}

Intra- and interreader agreement is shown in Table 4 . There were no significant mean differences between readers $(P>.05)$. The overall intra- and interreader measurements showed excellent agreement, with ICCs of $>0.97$.

\section{Aneurysms with Intraluminal Thrombus}

Ten aneurysms were found with intraluminal thrombus: 3 aneurysms located in the middle cerebral artery, 2 located in the internal carotid artery, 2 located in the anterior communicating artery, 2 located in the posterior communicating artery, and 1 located in the basilar artery. Aneurysm sizes ranged from 8.0 to $28.2 \mathrm{~mm}$. 3D-BB MR imaging gave the best evaluation of aneurysm dimensions, with clear delimitation of both the lumen and thrombus (Fig 3). The median thickness of the intraluminal thrombus was $2.8 \mathrm{~mm}$ (IQR, 0.8-4.4 mm).

AJNR Am J Neuroradiol 40:960-66 Jun 2019 www.ajnr.org 963 
Table 4: Intra- and interreader agreement for aneurysm measurements

\begin{tabular}{|c|c|c|c|c|}
\hline & $\begin{array}{c}\text { CV } \\
(100 \%)\end{array}$ & Bias & LOA & ICC \\
\hline \multicolumn{4}{|c|}{ Intrareader agreement } & \\
\hline TOF-MRA & 7.02 & 0.19 & $(-0.87-1.25)$ & $0.99(0.98-0.99)$ \\
\hline CE-MRA & 6.71 & 0.14 & $(-1.09-1.37)$ & $0.99(0.98-0.99)$ \\
\hline 3D-BB MRI & 6.37 & -0.08 & $(-1.18-1.02)$ & $0.99(0.98-0.99)$ \\
\hline 3DRA & 6.87 & 0.14 & $(-1.04-1.32)$ & $0.99(0.98-0.99)$ \\
\hline \multicolumn{5}{|l|}{ Width } \\
\hline TOF-MRA & 6.94 & 0.06 & $(-0.99-1.12)$ & $0.99(0.98-0.99)$ \\
\hline CE-MRA & 6.45 & 0.10 & $(-1.13-1.33)$ & $0.99(0.98-0.99)$ \\
\hline 3D-BB MRI & 6.31 & 0.18 & $(-0.92-1.28)$ & $0.99(0.98-0.99)$ \\
\hline 3DRA & 6.25 & 0.11 & $(-1.00-1.23)$ & $0.99(0.98-0.99)$ \\
\hline \multicolumn{5}{|l|}{ Neck } \\
\hline TOF-MRA & 7.29 & 0.18 & $(-1.04-1.39)$ & $0.98(0.98-0.99)$ \\
\hline CE-MRA & 7.05 & 0.13 & $(-0.93-1.19)$ & $0.99(0.98-0.99)$ \\
\hline 3D-BB MRI & 6.72 & 0.14 & $(-0.90-1.18)$ & $0.99(0.98-0.99)$ \\
\hline 3DRA & 6.98 & -0.08 & $(-1.17-1.02)$ & $0.99(0.98-0.99)$ \\
\hline \multicolumn{5}{|l|}{ Overall } \\
\hline TOF-MRA & 7.08 & 0.14 & $(-0.78-1.06)$ & $0.99(0.98-0.99)$ \\
\hline CE-MRA & 6.78 & 0.12 & $(-1.06-1.30)$ & $0.99(0.98-0.99)$ \\
\hline 3D-BB MRI & 6.51 & 0.08 & $(-0.96-1.12)$ & $0.99(0.98-0.99)$ \\
\hline 3DRA & 6.75 & 0.06 & $(-1.04-1.16)$ & $0.99(0.98-0.99)$ \\
\hline \multicolumn{5}{|c|}{ Interreader agreement } \\
\hline \multicolumn{5}{|c|}{ Height } \\
\hline TOF-MRA & 8.12 & 0.02 & $(-1.45-1.49)$ & $0.98(0.98-0.99)$ \\
\hline CE-MRA & 8.19 & 0.23 & $(-1.33-1.80)$ & $0.98(0.98-0.99)$ \\
\hline 3D-BB MRI & 8.03 & 0.03 & $(-1.50-1.56)$ & $0.98(0.98-0.99)$ \\
\hline 3DRA & 7.87 & -0.07 & $(-1.58-1.44)$ & $0.98(0.98-0.99)$ \\
\hline \multicolumn{5}{|l|}{ Width } \\
\hline TOF-MRA & 8.03 & -0.03 & $(-1.50-1.44)$ & $0.98(0.98-0.99)$ \\
\hline CE-MRA & 7.55 & 0.17 & $(-1.30-1.64)$ & $0.99(0.98-0.99)$ \\
\hline 3D-BB MRI & 8.37 & 0.03 & $(-1.61-1.67)$ & $0.98(0.98-0.99)$ \\
\hline 3DRA & 7.15 & -0.13 & $(-1.54-1.28)$ & $0.99(0.98-0.99)$ \\
\hline \multicolumn{5}{|l|}{ Neck } \\
\hline TOF-MRA & 8.96 & 0.18 & $(-0.74-1.10)$ & $0.97(0.95-0.98)$ \\
\hline CE-MRA & 8.81 & 0.07 & $-0.81-1.07)$ & $0.98(0.97-0.99)$ \\
\hline 3D-BB MRI & 8.95 & 0.14 & $(-0.72-1.00)$ & $0.98(0.97-0.99)$ \\
\hline 3DRA & 8.82 & 0.10 & $(-0.82-0.98)$ & $0.98(0.97-0.99)$ \\
\hline \multicolumn{5}{|l|}{ Overall } \\
\hline TOF-MRA & 8.44 & 0.06 & $(-0.78-1.06)$ & $0.98(0.98-0.99)$ \\
\hline CE-MRA & 8.16 & 0.16 & $(-0.74-0.98)$ & $0.98(0.98-0.99)$ \\
\hline 3D-BB MRI & 8.43 & 0.07 & $(-0.63-0.93)$ & $0.98(0.98-0.99)$ \\
\hline 3DRA & 8.15 & -0.03 & $(-0.72-1.00)$ & $0.98(0.98-0.99)$ \\
\hline
\end{tabular}

sive with procedural risks such as arterial dissection, hematomas, stroke, and even death that are more important than the small theoretic risks of radiation and contrast exposure. ${ }^{18}$ Alternatively, CTA is a fast, noninvasive imaging test that is often used in first-line aneurysm assessment. CTA has widespread availability and has been shown to be of benefit in not only aneurysm detection ${ }^{19-23}$ but also presurgical planning. ${ }^{24}$ Despite the advantages of CTA, like DSA, CTA uses radiation and iodinated contrast, reducing its adoption in UIA screening and monitoring. ${ }^{12}$ MR imaging does not have these issues. ${ }^{25}$ Other disadvantages of CTA include the fact that despite the development of improved techniques in the region of the skull base, ${ }^{26,27}$ MR imaging lacks the attenuation and streak artifacts occasionally encountered in CTA. ${ }^{28}$ MR imaging can play a major role in UIA detection, monitoring, and treatment planning. ${ }^{29}$

3D-TOF and CE-MRA are commonly used methods for UIA evaluation. 3DTOF-MRA is a popular method because it does not require a contrast agent ${ }^{10,30,31}$; however, it has flow artifacts and can confuse T1-weighted hyperintense thrombus within an aneurysm with flow-related enhancement. $^{32,33}$ Bright thrombus can mimic flowing lumen, and isointense thrombus is difficult to distinguish from surrounding brain tissue. ${ }^{15}$ TOF-MRA can also make detection of IAs difficult in the setting of $\mathrm{T} 1$ hyperintense intraparenchymal or subarachnoid hemorrhage. ${ }^{34-36}$ Our study observed that while still similar to 3DRA, 3D-TOF-

\section{DISCUSSION}

In this study, measurements obtained on 3D-BB MR imaging were in close agreement with 3DRA measurements and had a better accuracy than 3D-TOF with less than half the TOF measurement error. The sample size needed to measure aneurysm size change in longitudinal studies would be reduced by $84 \%$ using 3D-BB MR imaging compared with using 3D-TOF. Our results support the use of noncontrast 3D-BB MR imaging for intracranial aneurysm surveillance. Despite previous studies evaluating the use of BB MR imaging sequences in the characterization of IAs, this is the first study to validate $3 \mathrm{D}-\mathrm{BB} \mathrm{MR}$ imaging against the criterion standard 3DRA for aneurysm morphology measurements. In addition, this is the first study to compare 3D-BB MR imaging with 3D-TOF and CE-MRA for IA measurement accuracy.

Although 3DRA remains the criterion standard in aneurysm evaluation and treatment planning with high spatial resolution and excellent hemodynamic temporal resolution, ${ }^{11}$ DSA is inva-
MRA had the least accuracy of the MR imaging-based methods tested, in accordance with previous literature.

CE-MRA is an accurate method for UIA evaluation because it is not flow-dependent. ${ }^{37}$ CE-MRA was shown to be superior to 3D-TOF-MRA for assessment of sac shape, visualizing an aneurysm neck, calculating of the sac/neck ratio, and identifying branches originating from the sac and/or neck, ${ }^{5}$ especially for large aneurysms ( $>13 \mathrm{~mm}$ ), when flow artifacts were commonly present. Despite these advantages of CE-MRA, its limitations include the use of gadolinium-based contrast media, dependence on timing of contrast administration that may lead to venous contamination, and radiofrequency power deposition at high field strengths. ${ }^{38}$ Recent concerns regarding gadolinium deposition in the brain parenchyma, while uncertain and controversial, call into question its widespread use in repeat imaging for surveillance. ${ }^{39}$

When we compared it with other imaging modalities, 3D-BB 
MR imaging has clear advantages. First, it is an accurate method for UIA measurements as evidenced in the superior agreement of this study with DSA, which was comparable with CE-MRA. Although our CE-MRA protocol had better resolution (around 0.7 $\mathrm{mm}$ isotropic) than most routine clinical protocols $(0.9-1.1$ $\mathrm{mm}),{ }^{5}$ 3D-BB MR imaging had an even higher resolution (0.5 $\mathrm{mm}$ isotropic), which may explain its slightly improved accuracy. 3D-BB MR imaging has also been used for intracranial stenosis quantification $^{11}$ and extracranial carotid plaque imaging ${ }^{40}$ in studies showing excellent agreement with DSA. Our study extends these observations in showing that $3 \mathrm{D}-\mathrm{BB}$ MR imaging provides accurate assessment of aneurysms. The high accuracy of 3D-BB MR imaging is favorable for future longitudinal studies, which can reduce sample size more significantly than with 3DTOF and reduce the cost of the clinical trial. Accurate quantification of aneurysm growth is important because fast-growing aneurysms have a much higher risk of rupture. ${ }^{41,42}$

Second, as a noncontrast acquisition, 3D-BB MR imaging is ideal for repeat, routine surveillance of UIAs compared with contrast techniques including CE-MRA and CTA. It can also be repeated if the first acquisition fails due to patient motion or other issues. Third, 3D-BB SPACE is insensitive to flow artifacts, which is superior to 3D-TOF (Figs 3 and 4). The 3D fast-spin-echo BB sequence is inherently blood-suppressed. ${ }^{43}$ Although in large aneurysms, flow artifacts can still occur, several additional techniques, including improved motion-sensitized driven-equilibrium $^{44}$ and delay alternating with nutation for tailored excitation (DANTE) $)^{45}$ may be used to optimize blood suppression. Previous work comparing $3 \mathrm{D}-\mathrm{TOF}$ and $\mathrm{BB}$ techniques showed significant advantages to $\mathrm{BB}$ imaging in cases of large aneurysms or slow blood flow. ${ }^{36,46}$ In 1 study, the authors found 3 patients in whom the aneurysm was not demonstrated on 3D-TOF due to the presence of local hematoma, but by performing a $\mathrm{BB}$ sequence, they found that all of the IAs were subsequently identified without the need for contrast. ${ }^{15}$

Last, 3D-BB MR imaging can also visualize intraluminal thrombus and the vessel wall, which is a unique advantage in comparison with angiographic methods. Because vessel wall features and postcontrast enhancement have been studied as potential markers of aneurysm rupture, ${ }^{25,47}$ this ability could become increasingly important in aneurysm characterization and monitoring.

\section{Limitations}

There are some limitations to this study. First, we evaluated only saccular aneurysms with fusiform aneurysms excluded. Second, our current 3D-BB MR imaging sequence has a scan time of approximately 9 minutes, greater than the time it takes for either CE-MRA (2-3 minutes) or TOF ( $\sim 5$ minutes). It is possible that a lower resolution $(0.6-0.7 \mathrm{~mm}$ isotropic) can achieve sufficient accuracy with a significantly reduced scan time. Advanced acceleration techniques, including compressed sensing, may potentially reduce the scan time significantly with similar image quality. ${ }^{48}$ Future studies are needed to determine the minimum spatial resolution necessary and apply new acceleration techniques clinically. Third, the image-reconstruction methods were not the same across imaging modalities. We used the reconstruction methods that were conventionally used in clinical routine, ${ }^{15,49,50}$ and also note that the influence of reconstruction methods for aneurysm measurements has been rarely studied. However, we believe the differences caused by reconstruction methods were much less than the differences caused by imaging techniques, as shown in our data.

Despite these limitations, we believe that they are offset by the improved IA measurements compared with the other MR imaging techniques as well as the ability of $3 \mathrm{D}-\mathrm{BB} \mathrm{MR}$ imaging to characterize the vessel wall without the use of gadolinium-based contrast, supporting the use of noncontrast $\mathrm{BB}$ MR imaging to replace CE-MRA in monitoring IAs.

\section{CONCLUSIONS}

3D-BB MR imaging achieves superior accuracy for intracranial aneurysm size measurements over 3D-TOF using 3DRA as the criterion standard, though all MR imaging measurements did not significantly differ from those with 3DRA. This noncontrast technique is promising for clinical surveillance of patients with unruptured intracranial aneurysms.

Disclosures: Christopher Hess—UNRELATED: Expert Testimony: various medicolegal firms; Grants/Grants Pending: National Institutes of Health*; Travel/Accommodations/Meeting Expenses Unrelated to Activities Listed: Korean Society of Radiology, MRI Garmisch Symposium, Comments: Korean Society of Radiology; travel costs to lecture and participate in Korean Congress of Radiology 2018 and 18th MRI International MRI Symposium Garmisch-Partenkirchen. *Money paid to individual.

\section{REFERENCES}

1. Wiebers DO, Whisnant JP, Huston J 3rd, et al; International Study of Unruptured Intracranial Aneurysms Investigators. Unruptured intracranial aneurysms: natural history, clinical outcome, and risks of surgical and endovascular treatment. Lancet 2003;362:103-10 CrossRef Medline

2. Fogelholm R, Hernesniemi J, Vapalahti M. Impact of early surgery on outcome after aneurysmal subarachnoid hemorrhage: a population-based study. Stroke 1993;24:1649-54 CrossRef Medline

3. Passier PE, Visser-Meily JM, Rinkel GJ, et al. Life satisfaction and return to work after aneurysmal subarachnoid hemorrhage. $J$ Stroke Cerebrovasc Dis 2011;20:324-29 CrossRef Medline

4. Rinkel GJ, Algra A. Long-term outcomes of patients with aneurysmal subarachnoid haemorrhage. Lancet Neurol 2011;10:349-56 CrossRef Medline

5. Cirillo M, Scomazzoni F, Cirillo L, et al. Comparison of 3D TOFMRA and 3D CE-MRA at 3T for imaging of intracranial aneurysms. Eur J Radiol 2013;82:e853-59 CrossRef Medline

6. Komotar RJ, Starke RM, Connolly ES. The natural course of unruptured cerebral aneurysms. Neurosurgery 2012;71:N7-9 CrossRef Medline

7. Backes D, Vergouwen MD, Tiel Groenestege AT, et al. PHASES score for prediction of intracranial aneurysm growth. Stroke 2015;46: 1221-26 CrossRef Medline

8. Gibbs GF, Huston J 3rd, Bernstein MA, et al. Improved image quality of intracranial aneurysms: 3.0-T versus 1.5-T time-of-flight MR angiography. AJNR Am J Neuroradiol 2004;25:84-87 Medline

9. Nael K, Villablanca JP, Mossaz L, et al. 3T contrast-enhanced MR angiography in evaluation of suspected intracranial aneurysm: comparison with MDCT angiography. AJR Am J Roentgenol 2008; 190:389-95 CrossRef Medline

10. Anzalone N, Scomazzoni F, Cirillo M, et al. Follow-up of coiled cerebral aneurysms at 3T: comparison of 3D time-of-flight MR angiography and contrast-enhanced MR angiography. AJNR Am J Neuroradiol 2008;29:1530-36 CrossRef Medline

11. Park JE, Jung SC, Lee SH, et al. Comparison of 3D magnetic reso- 
nance imaging and digital subtraction angiography for intracranial artery stenosis. Eur Radiol 2017;27:4737-46 CrossRef Medline

12. van der Schaaf IC, Velthuis BK, Wermer MJ, et al; ASTRA Study Group. New detected aneurysms on follow-up screening in patients with previously clipped intracranial aneurysms: comparison with DSA or CTA at the time of SAH. Stroke 2005;36:1753-58 CrossRef Medline

13. Wermer MJ, Buskens E, van der Schaaf IC, et al. Yield of screening for new aneurysms after treatment for subarachnoid hemorrhage. Neurology 2004;62:369-75 CrossRef Medline

14. Wermer MJ, van der Schaaf IC, Velthuis BK, et al. Yield of short-term follow-up CT/MR angiography for small aneurysms detected at screening. Stroke 2006;37:414-18 CrossRef Medline

15. Stivaros SM, Harris JN, Adams W, et al. Does black blood MRA have a role in the assessment of intracerebral aneurysms? Eur Radiol 2009;19:184-92 CrossRef Medline

16. Zhu C, Haraldsson $\mathrm{H}$, Tian $\mathrm{B}$, et al. High resolution imaging of the intracranial vessel wall at 3 and $7 \mathrm{~T}$ using 3D fast spin echo MRI. MAGMA 2016;29:559-70 CrossRef Medline

17. Zhang X, Zhu C, Peng W, et al. Scan-rescan reproducibility of high resolution magnetic resonance imaging of atherosclerotic plaque in the middle cerebral artery. PLoS One 2015;10:e134913 CrossRef Medline

18. Kaufmann TJ, Huston J 3rd, Mandrekar JN, et al. Complications of diagnostic cerebral angiography: evaluation of 19,826 consecutive patients. Radiology 2007;243:812-19 CrossRef Medline

19. Tipper G, U-King-Im JM, Price SJ, et al. Detection and evaluation of intracranial aneurysms with 16-row multislice CT angiography. Clin Radiol 2005;60:565-72 CrossRef Medline

20. Chen CY, Hsieh SC, Choi WM, et al. Computed tomography angiography in detection and characterization of ruptured anterior cerebral artery aneurysms at uncommon location for emergent surgical clipping. Clin Imaging 2006;30:87-93 CrossRef Medline

21. Carstairs SD, Tanen DA, Duncan TD, et al. Computed tomographic angiography for the evaluation of aneurysmal subarachnoid hemorrhage. Acad Emerg Med 2006;13:486-92 CrossRef Medline

22. Uysal E, Yanbuloğlu B, Ertürk M, et al. Spiral CT angiography in diagnosis of cerebral aneurysms of cases with acute subarachnoid hemorrhage. Diagn Interv Radiol 2005;11:77-82 Medline

23. Goddard AJ, Tan G, Becker J. Computed tomography angiography for the detection and characterization of intra-cranial aneurysms: current status. Clin Radiol 2005;60:1221-36 CrossRef Medline

24. Suzuki Y, Nakajima M, Ikeda H, et al. Preoperative evaluation of the venous system for potential interference in the clipping of cerebral aneurysm. Surg Neurol 2004;61:357-64; discussion 364 CrossRef Medline

25. Edjlali M, Gentric JC, Régent-Rodriguez C, et al. Does aneurysmal wall enhancement on vessel wall MRI help to distinguish stable from unstable intracranial aneurysms? Stroke 2014;45:3704-06 CrossRef Medline

26. Tomandl BF, Hammen T, Klotz E, et al. Bone-subtraction CT angiography for the evaluation of intracranial aneurysms. AJNR Am J Neuroradiol 2006;27:55-59 Medline

27. Sakamoto S, Kiura Y, Shibukawa M, et al. Subtracted 3D CT angiography for evaluation of internal carotid artery aneurysms: comparison with conventional digital subtraction angiography. AJNR Am J Neuroradiol 2006;27:1332-37 Medline

28. Kouskouras C, Charitanti A, Giavroglou C, et al. Intracranial aneurysms: evaluation using CTA and MRA: correlation with DSA and intraoperative findings. Neuroradiology 2004;46:842-50 CrossRef Medline

29. Vaphiades MS, Horton JA. MRA or CTA, that's the question. Surv Ophthalmol 2005;50:406-10 CrossRef Medline

30. Kähärä V. Postprocedural monitoring of cerebral aneurysms. Acta Radiol 2006;47:320-27 CrossRef Medline

31. Okahara M, Kiyosue H, Hori Y, et al. Three-dimensional time-offlight MR angiography for evaluation of intracranial aneurysms after endosaccular packing with Guglielmi detachable coils: comparison with 3D digital subtraction angiography. Eur Radiol 2004;14: 1162-68 Medline
32. Moody AR, Pollock JG, O'Connor AR, et al. Lower-limb deep venous thrombosis: direct MR imaging of the thrombus. Radiology 1998; 209:349-55 CrossRef Medline

33. Derdeyn CP, Graves VB, Turski PA, et al. MR angiography of saccular aneurysms after treatment with Guglielmi detachable coils: preliminary experience. AJNR Am J Neuroradiol 1997;18:279-86 Medline

34. Jäger HR, Ellamushi $H$, Moore EA, et al. Contrast-enhanced MR angiography of intracranial giant aneurysms. AJNR Am J Neuroradiol 2000;21:1900-07 Medline

35. Evans AL, Coley SC, Wilkinson ID, et al. First-line investigation of acute intracerebral hemorrhage using dynamic magnetic resonance angiography. Acta Radiol 2005;46:625-30 CrossRef Medline

36. Thomas B, Sunaert S, Thamburaj K, et al. Spurious absence of signal on 3D time-of-flight MR angiograms on 1 and 3 Tesla magnets in cerebral arteries associated with a giant ophthalmic segment aneurysm: the need for alternative techniques. JBR-BTR 2005;88: 241-44 Medline

37. Okumura A, Araki Y, Nishimura Y, et al. The clinical utility of contrast-enhanced 3D MR angiography for cerebrovascular disease. Neurol Res 2001;23:767-71 CrossRef Medline

38. Bernstein MA, Huston J 3rd, Lin C, et al. High-resolution intracranial and cervical MRA at 3.0T: technical considerations and initial experience. Magn Reson Med 2001;46:955-62 CrossRef Medline

39. McDonald RJ, McDonald JS, Kallmes DF, et al. Intracranial gadolinium deposition after contrast-enhanced MR imaging. Radiology 2015;275:772-82 CrossRef Medline

40. Zhao H, Wang J, Liu X, et al. Assessment of carotid artery atherosclerotic disease by using three-dimensional fast black-blood MR imaging: comparison with DSA. Radiology 2015;274:508-16 CrossRef Medline

41. Mehan WA Jr, Romero JM, Hirsch JA, et al. Unruptured intracranial aneurysms conservatively followed with serial CT angiography: could morphology and growth predict rupture? J Neurointerv Surg 2014;6:761-66 CrossRef Medline

42. Villablanca JP, Duckwiler GR, Jahan R, et al. Natural history of asymptomatic unruptured cerebral aneurysms evaluated at $\mathrm{CT}$ angiography: growth and rupture incidence and correlation with epidemiologic risk factors. Radiology 2013;269:258-65 CrossRef Medline

43. Zhu C, Sadat U, Patterson AJ, et al. 3D high-resolution contrast enhanced MRI of carotid atheroma: a technical update. Magn Reson Imaging 2014;32:594-97 CrossRef Medline

44. Zhu C, Graves MJ, Yuan J, et al. Optimization of improved motionsensitized driven-equilibrium (iMSDE) blood suppression for carotid artery wall imaging. J Cardiovasc Magn Reson 2014;16:61 CrossRef Medline

45. Viessmann O, Li L, Benjamin P, et al. T2-weighted intracranial vessel wall imaging at 7 Tesla using a DANTE-prepared variable flip angle turbo spin echo readout (DANTE-SPACE). Magn Reson Med 2017; 77:655-63 CrossRef Medline

46. Naganawa S, Ito T, Shimada H, et al. Cerebral black blood MR angiography with the interleaved multi-slab three-dimensional fast spin echo sequence. Radiat Med 1997;15:385-88 Medline

47. Wang $\mathrm{X}$, Zhu $\mathrm{C}$, Leng $\mathrm{Y}$, et al. Intracranial aneurysm wall enhancement associated with aneurysm rupture: a systematic review and meta-analysis. Acad Radiol 2018 Jun 13. [Epub ahead of print] CrossRef Medline

48. Zhu C, Tian B, Chen L, et al. Accelerated whole brain intracranial vessel wall imaging using black blood fast spin echo with compressed sensing (CS-SPACE). MAGMA 2018;31:457-67 CrossRef Medline

49. van Rooij WJ, Sprengers ME, de Gast AN, et al. 3D rotational angiography: the new gold standard in the detection of additional intracranial aneurysms. AJNR Am J Neuroradiol 2008;29:976-79 CrossRef Medline

50. HaiFeng L, YongSheng X, YangQin X, et al. Diagnostic value of 3D time-of-flight magnetic resonance angiography for detecting intracranial aneurysm: a meta-analysis. Neuroradiology 2017;59:1083-92 CrossRef Medline 
$\mathbf{T}$

he authors regret that in the article "Surveillance of Unruptured Intracranial Saccular Aneurysms Using Noncontrast 3D-BlackBlood MRI: Comparison of 3D-TOF and Contrast-Enhanced MRA with 3D-DSA" (AJNR Am J Neuroradiol 2019;40:960-66), the legend for Fig 4 did not match the figure. A corrected legend with the original figure is reproduced below.

http://dx.doi.org/10.3174/ajnr.A6206

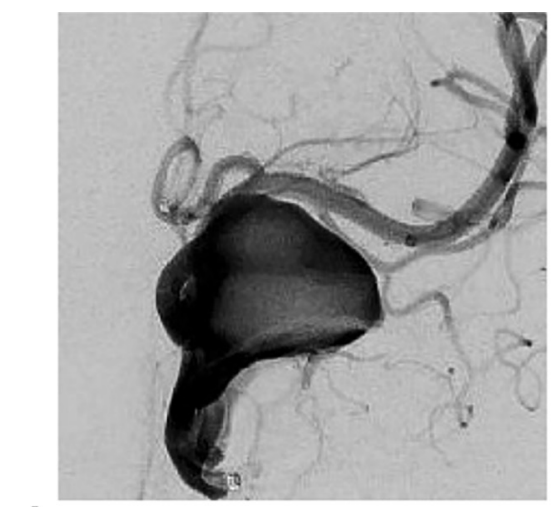

A

DSA

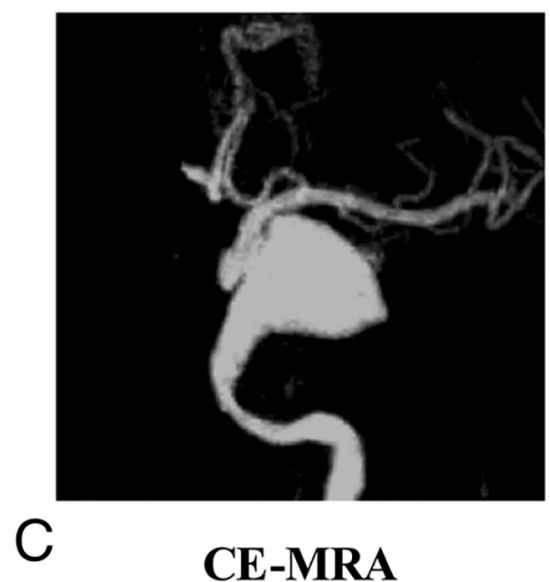

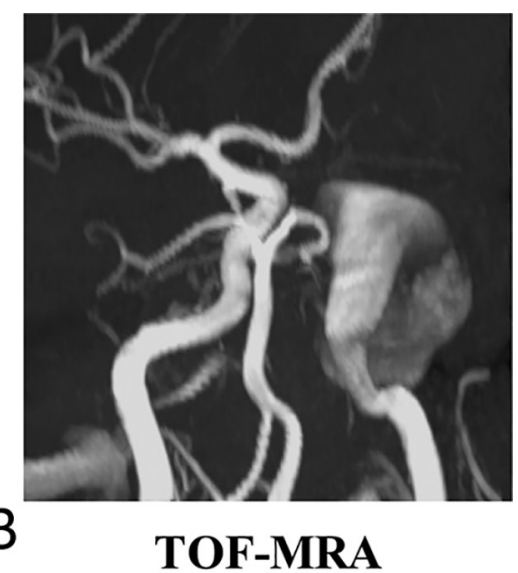

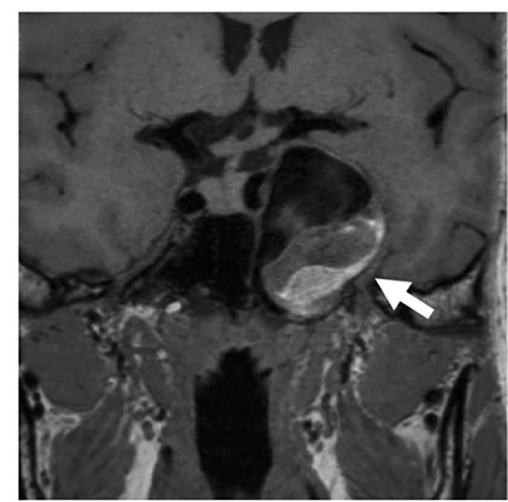

\section{D BB MR}

FIG 4. $A, A$ 63-year-old woman with a right internal carotid artery aneurysm on DSA. 3D black-blood (BB) SPACE (D) can clearly visualize the sac and intraluminal thrombus of the aneurysm, which is superior to DSA (A), TOF-MRA (B), and contrast-enhanced (CE)-MRA (C). 